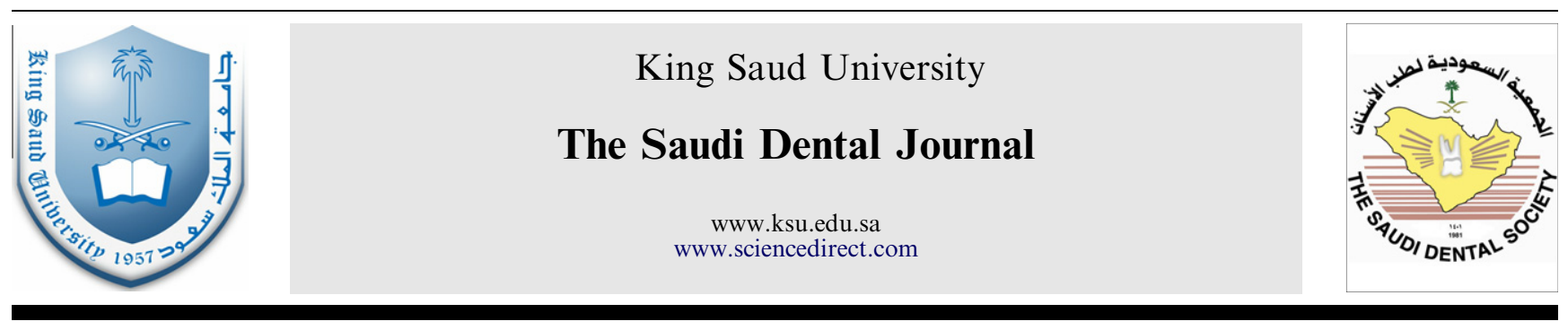

\title{
EDITORIAL
}

\section{To publish or not to publish, that is the question}

In an era of rapid technologic advancement in the world of communication, social networking, instant messaging, Facebook, Twitter, etc., it is virtually impossible to be isolated even if you want to be. The whole paradigm of obtaining information and the power it brings has shifted. Seeking information used to be a laborious task, but now information is just a few clicks away.

But how does this relate to the publishing of dental research? Simply speaking, the dental student or clinician who is the end-user - the consumer of the published word - has become more astute and more demanding. Hence, it behooves dental educators and researchers who wish to publish to cater to the needs of these stake-holders. These people want accurate and reliable information - and they want it now. With Google becoming an actual verb ("I will google it") the reader is bombarded with a tsunami of sources for information and the onus is on him or her to judge the accuracy and reliability of the obtained information. Take Wikipedia as an example; anyone can upload information in a very dynamic fashion. Even if one wants to get information about a certain clinical procedure or technique, a quick search will provide not only a multitude of written explanations, but more often than not several videos showing in a very graphical way how it's done. This applies equally to whether you want to know how to make bread from scratch or clean the track ball of your blackberry.

But going back to the subject of dental publishing, yes I would like to publish but I will be very picky when it comes to which journal I will submit my manuscript to. Of prime importance, I would like to know in which and how many indexing services the journal is available in. There are a plethora of such services like Medline, PubMed and Scopus to name a few. I obviously want my paper to be as widely accessible as possible. I challenge any author to deny that he or she gets a kick out of learning that his or her paper has been cited. After all, is not it all about the dissemination of information and knowledge? Moreover, many of the reputable publishers will now alert the author when their work has been cited elsewhere.

So let this be an open and standing invitation to all the readers to become inspired to actually participate and become authors themselves and to embark on sound research projects which can in turn be published. It is only with the economics of knowledge that nations advance and develop. What might seem as such an insurmountable task is actually a wonderful and rewarding journey. It all usually starts with a simple idea and then when you read the final product you say to yourself, "Why did not I think of that?"

Esam Tashkandi Associate Professor Department of Prosthetic Dental Sciences, College of Dentistry, King Saud University, Riyadh, Saudi Arabia

and

Associate Editor-in-Chief

Saudi Dental Journal

E-mail address: esamtash@ksu.edu.sa

1013-9052 @ 2011 King Saud University. Production and hosting by Elsevier B.V. All rights reserved.

Peer review under responsibility of King Saud University. doi:10.1016/j.sdentj.2011.02.005

\begin{tabular}{|c|c|}
\hline$\frac{5}{\text { ELSEVIER }}$ & Production and hosting by Elsevier \\
\hline
\end{tabular}

